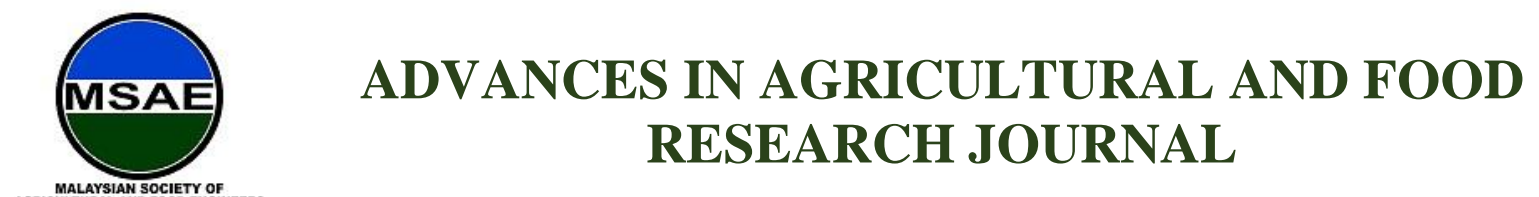

HH PUBLISHER

Original Research Paper

\title{
Evaluation of Soil Stabilizer in Oil Palm Plantation Road Construction
}

\author{
Abd Rahim Shuib*, Mohd Khairul Fadzly Md Radzi, Aminulrashid Mohamed, Mohd Ramdhan Mohd Khalid \\ Malaysian Palm Oil Board (MPOB), No. 6, Persiaran Institusi, Bandar Baru Bangi, 43000 Kajang, Selangor, \\ Malaysia.
}

*Corresponding author: Abd Rahim Shuib, Malaysian Palm Oil Board (MPOB), No 6, Persiaran Institusi Bandar Baru Bangi, 43000 Kajang, Selangor, Malaysia; rahim.shuib2@gmail.com.

\begin{abstract}
Plantation road construction is an important part that requires a serious planning. Any negligence in constructing and maintaining the roads will affect the infield transportation time of the harvested agricultural products as well as the process of bringing out the agricultural products to the needs. Moreover, weather conditions will make the roads impassable and create poor road surfaces which cause damage to the vehicles. Hence, without regular maintenance and resurfacing, these_roads will have limited useful lives. This paper has done the laboratory work to evaluate the unconfined compressive strength of oil palm soil by using the FJ-Adtech additive stabilisers as an enhancing medium. Lahad Datu plantation soils were mixed well with additive loadings of $14 \mathrm{wt}$. $\%$ up to $20 \mathrm{wt} \%$ and being pressed at $100 \mathrm{kPa}$ in compacted form sample with the size of $100 \mathrm{~mm}$ (height) x $50 \mathrm{~mm}$ (diameter). The results showed that the FJ-Ad treatment effectively improved the strength characteristics of Lahad Datu soil $(4311 \mathrm{kPa})$ at $20 \mathrm{wt}$. \% of loading percentage compared to the untreatment soil $(1382 \mathrm{kPa})$. Field work observation also showed that the road construction surfaces treated with the stabiliser formulation showed less maintenance as $6 \%$ to $7 \%$ cheaper compared to the conventional method. Therefore, this additive stabiliser is suitable to be used as soil treatment in the formulation for making the road surfaces more durable, less permeable and less compressed than the native soil.
\end{abstract}

Keywords: Treatment; soil stabiliser; FJ-Adtech; road construction; oil palm plantation

Received: $10^{\text {th }}$ September 2020

Citation: Shuib AB, MdRadzi MKF, Mohamed A, et al. Evaluation of Soil Stabilizer in Oil

Accepted: $14^{\text {th }}$ October 2020

Palm Plantation Road Construction. Adv Agri

Food Res J 2020; 1(2): a0000122. https://doi.org/10.36877/aafrj.a0000122

Available Online: $31^{\text {st }}$ October 2020

\section{Introduction}

The Malaysian oil palm plantation area in 2019 is about 5.90 million hectares where Sabah is the second largest oil palm planted state with 1.54 million hectares (MPOB, 2020). The current standard practice in oil palm plantations is to construct $60 \mathrm{~m}$ of road per hectare 
of oil palm planted area (Phua, 2008). Thus, the state of Sabah alone needs about 300,000 $\mathrm{km}$ of roads in the oil palm plantations. Despite the length of these roads, minimal action has been taken to improve the road constructions. In order for an estate to have a good road network, the qualities of road constructions are major priority that needs serious considerations and plannings. It is important for a road system to be well designed, constructed and maintained for full efficiency. Improper road condition will cost the plantation to incur down time in most of the operations which then lead to inefficient in agriculture productions and affect the field activities (Asgari et al., 2015; Kushwaha et al., 2018).

Soils found in oil palm estates vary from peat to clay (Veloo et al., 2015; Paramananthan, 2013). Estates with lateritic soils have better and more stable roads in wet season. This is different from the estates with natural clay soils because they will have compactly structured road during the dry season but adversely during the wet season. It is due to the clay soil textures where the clay particles swell when absorbing water, causing the bonding to fail and break the road surface, then inevitably form potholes. These potholes are dangerous to the vehicles carrying heavy loads (Makusa, 2012). Sandy soils are the typical type of soils in the plantation area in Lahad Datu, Sabah. Sandy soils with poor clay content are known to cause problems in regard to utilisation and management. The soils are known to have very low moisture and nutrient retention capacities where any crops grown on the soils are susceptible to moisture stress as well as multiple nutrient deficiency problems. Besides that, high surface temperatures are also the common problems where soils with a cemented sporadic horizon cause floods in wet seasons, in addition to giving moisture stress to the crops in dry seasons (Afandi et al., 2001; Paramananthan, 2013).

Commonly, stabilising process on soil is performed by using bulk powder products such as acids, portal cements and fly ashes through several methods (REFs). Mechanical stabilisation is a physical technique which alters the physical nature of native soil particles either by inducing vibration or compaction, or by adding other physical properties such as barriers and nailing. Chemical stabilisation mainly depends on chemical reactions between stabiliser and soil minerals to achieve the desired effects on the final products (Firoozi et al., 2017; Singh et al., 2018). There is a stabiliser used for soil roads surfaces. Soil stabilisation is the modification of one or more soil properties to produce an enhanced soil substance with the desired properties of engineering. Soil stabilisation increases the strength of soil shear to give better load-bearing capability and increases soil permeability to enhance its resilience in resisting weathering cycle (Lim et al., 2014).

The dried additive powder called FJ-Adtech (FJ-Ad) is a special blended and concentrated hardening agent used for mixing agent with the original port land cement (OPC). One of the advantages using the FJ-Ad is it contains constituents with a high-water content, in that would solve the shrinkage cracks on setting, as is the case with conventional cement. It has the characteristics of setting rapidly after a definite time period, hence the total 
time required before the final setting is brief. Therefore, there is no need to waste much time for curing, and the road may be opened to traffic immediately. Other than that, FJ-Ad has a high dry density which sturdy against freezing and thawing. In addition, it is very stable chemically and its resistance against chemicals are unyielding.

This paper discussed a project concerning a plantation road construction work at the Malaysian Palm Oil Board (MPOB) Oil Palm Plantation, at Lahad Datu Station in Sabah. The project was carried out to improve the plantation roads by applying the FJ-Adtech soil stabiliser as an enhancing medium in the involved construction of the road. Results showed that this additive soil stabiliser was suitable to be used as a treatment in the related construction processes in making the road surface more durable, as well as less permeable and less compressed than the use of native soil.

\section{Materials and Methods}

\subsection{Preliminary work}

The main compositions of this FJ-Ad additive are sodium tripolyphosphate, lignin sulphate and stearate. The treatment additive used in this project was already mixed with OPC at certain percentage formulated by MALJAPA Sdn. Bhd. The comparison of physical properties between FJ-Ad and OPC are shown in Table 1.

Table 1. Comparison of physical properties of OPC and FJ-Ad.

\begin{tabular}{ccc}
\hline & $\begin{array}{c}\text { Ordinary Portland } \\
\text { Cement }\end{array}$ & FJ-Adtech \\
\hline Specific gravity $\left(\mathrm{g} / \mathrm{cm}^{3}\right)$ & 3.15 & 3.04 \\
Degree of pulverisation $(\%)$ & 88 screen remainder 10 & 88 screen remainder 5 \\
Relatives surface area $\left(\mathrm{cm}^{2} / \mathrm{g}\right)$ & 2.30 & 3.80 \\
\hline
\end{tabular}

The initial phase of this project was to identify the optimum percentage of FJ-Adtech additive that required in-situ soil for better binding and not loosening in the presence of moisture. Initially, both native and Lahad Datu soils were mixed well with additive for 30 minutes by dry mixing method at room temperature. Table 2 lists the formulation of the composition in the samples. Additive loadings of 14 to $20 \mathrm{wt}$. \% were applied for both types of soils. The mixture compositions were then poured into the test tube with the size of 100 $\mathrm{mm}$ (height) x $50 \mathrm{~mm}$ (diameter) before being pressed at $100 \mathrm{kPa}$ using the hand pressing device as illustrated in Figure 1. The compacted samples were evaluated by the unconfined compressive strength (ASTM D2166) properties with at least three replication specimens to obtain an average compressive strength and standard deviation results. 
Table 2. Composition of the mixture.

\begin{tabular}{ccc}
\hline \multirow{2}{*}{ Type of soil } & \multicolumn{2}{c}{ Composition mixture (wt. \%) } \\
\cline { 2 - 3 } & soil & FJ-Ad/OPC \\
\hline \multirow{2}{*}{ Lahad Datu (LDS) } & 86 & 14 \\
& 83 & 17 \\
& 80 & 20 \\
\hline \multirow{2}{*}{ Native (NS) } & 86 & 14 \\
& 83 & 17 \\
\end{tabular}

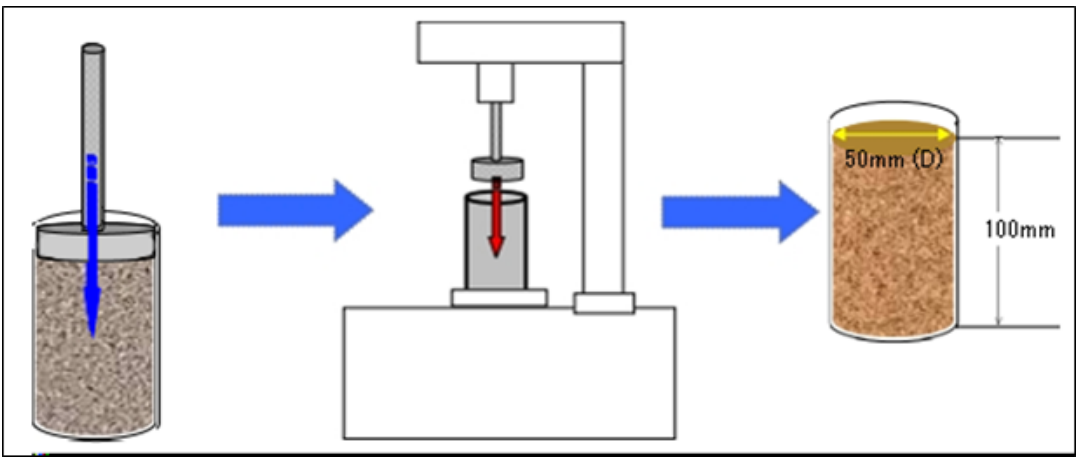

Figure 1. Compaction of treated soil using the pressing device.

\subsection{Field}

Figure 2 shows the flowchart of the road construction work which began by conducting the plantation site examination. The condition of the plantation sites was chosen based on the daily frequent travel by a trailer loaded with fresh fruit bunch (FFB), over 18 to 50 meters. Meanwhile, the quantity of additives composition (FJ-Ad and OPC) was determined by per $/ \mathrm{m}^{2}$ of soil condition at site. In this project, a custom-made pan mixer (Figure 3) was used for mixing of additive at construction site. The pan consisted 2.2 diameter of drum with a single blade propelled by an air-cooled diesel engine. The blade was rotating at $25 \mathrm{rpm}$ with engine speed of $1800 \mathrm{rpm}$. The pan volume of mixing is capable up to 400 $\mathrm{kg}$ of portland cement. Prior to that, preparation of works should be performed carefully as uneven levelling of ground would become the direct causes of unevenness in the finished surface through uneven thickness of executed layers. All vegetative remnants (like roots of trees and cobble stones) were completely removed from the surface of works, and lumps of soil were carefully smashed. The quantity of soil was reduced or added according to the thickness of works to be executed.

The next proceeding of work was to take action starting with skimming process. The soft layer of road surface was skimmed off and replaced with imported good soil from the nearby site. After that, the mixed additive composition was spread out along the road surface 
following the requirements per unit area. The mixing process of treatment composition with soil was done using the tractor with plough machine, an excavator and a backhoe. The mixing frequency happened at three to four times depending on the capacity of compaction machine. The materials were carefully mixed and rotovated until the colour became uniformly consistent with the controlling of water content as a precautionary step, in case it became dry. Finally, the compaction was poured out with the compaction rollers, and surface was checked for irregularity. The moisture content of the mixed soil should be close to the optimum moisture content for compaction. Since scaling was likely to develop in thin layers where unevenness was repaired by re-execution after the compaction, the mixed materials which had already been compacted was loosened up again and re-finished.

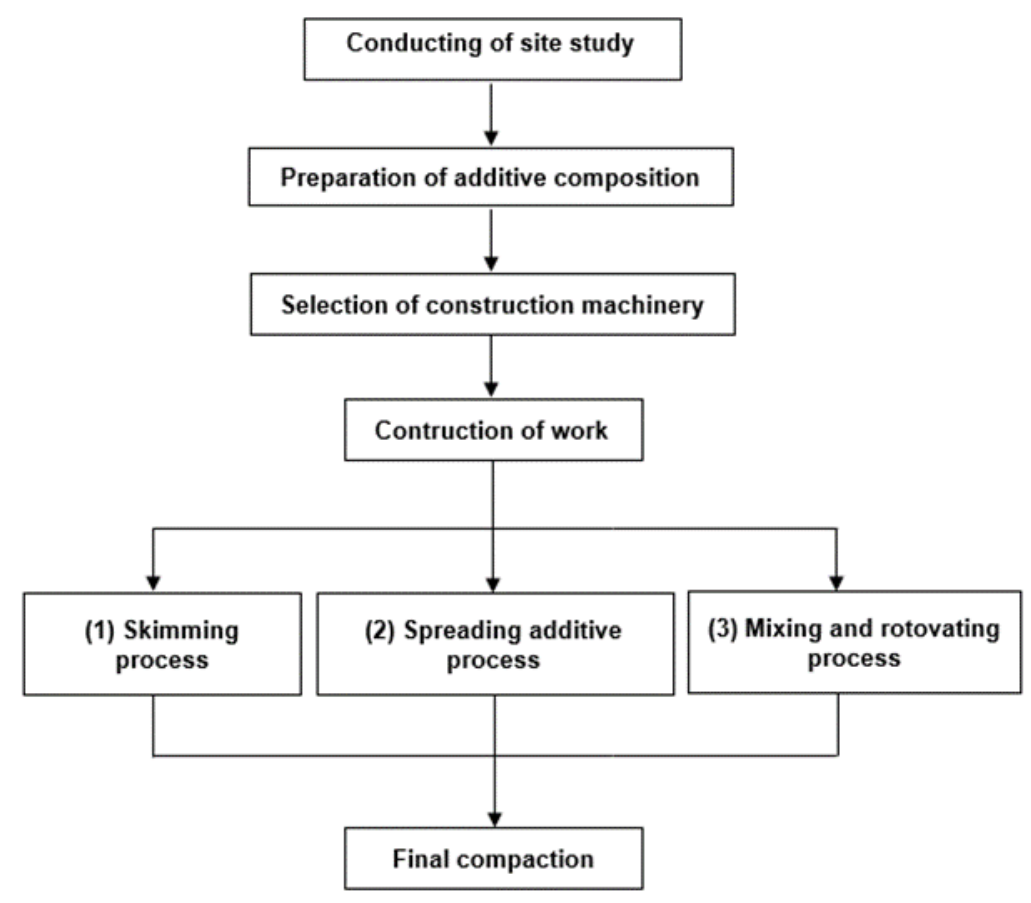

Figure 2. Flowchart for road construction process. 


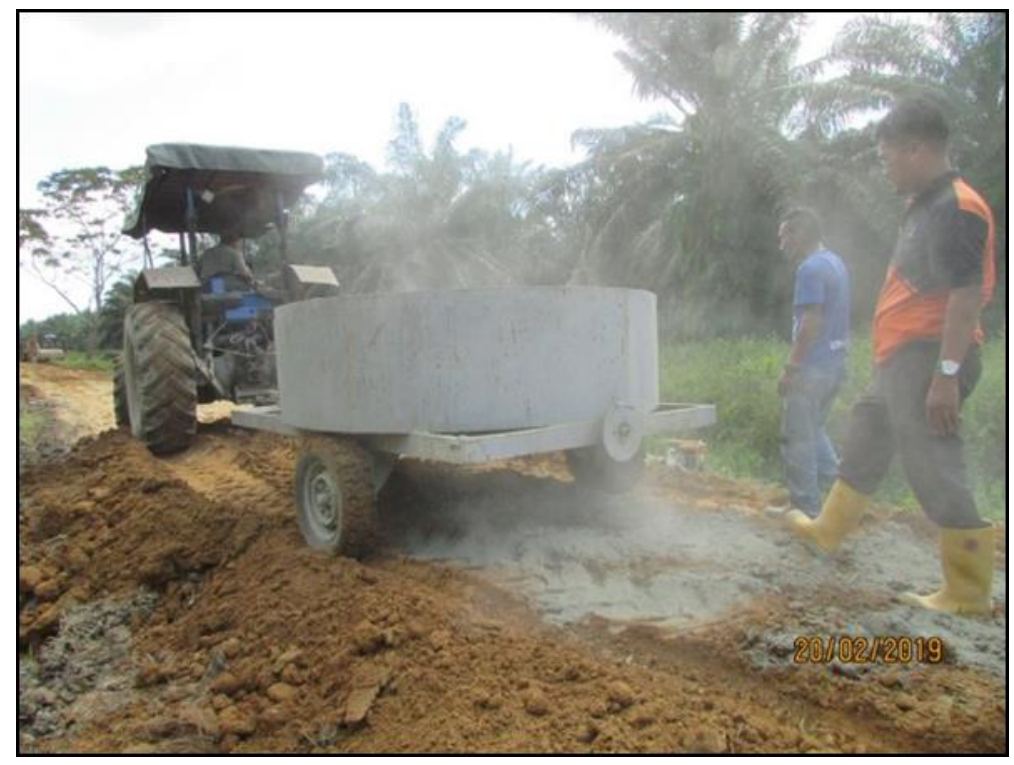

Figure 3. A custom-made pan mixer.

\section{Results and Discussions}

\subsection{Unconfined Compressive Strength}

Figure 4 illustrates the histogram pattern of unconfined compressive strength of Lahad Datu soil (LDS) and native soil (NS) which were treated with FJ-Adtech (FJ-Ad) at different weight percentages. The results clearly showed that the FJ-Ad treatment effectively improved the LDS strength's characteristics with the increase in weight percentage. It was obviously seen at $20 \mathrm{wt}$ \%, the FJ-Ad-LDS treated samples gained the highest compressive strength of $4311 \mathrm{kPa}$ as compared to the FJ-Ad-NS treated samples which was $1382 \mathrm{kPa}$. 


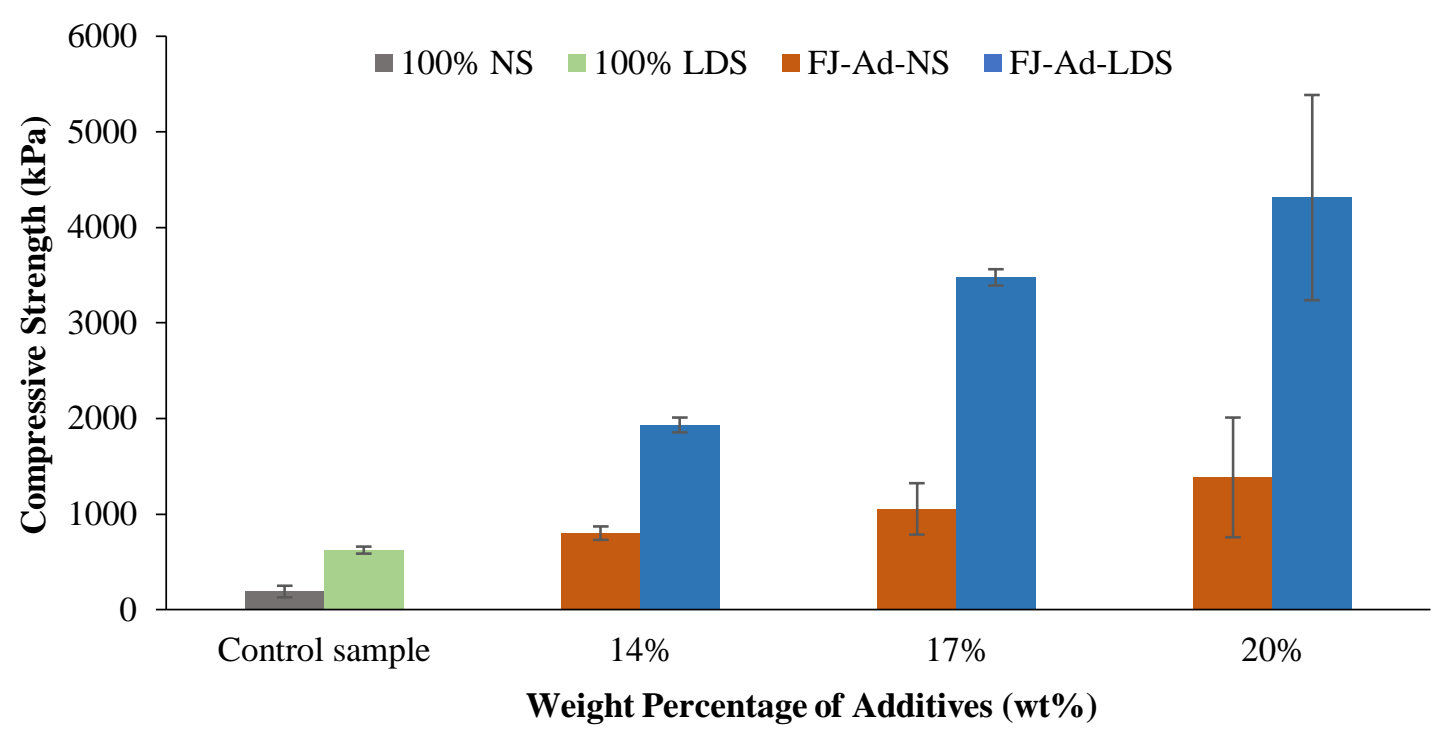

Figure 4. This Unconfined compressive strength of soil treatment samples at different weight percentage of additive materials.

\subsection{Construction}

\subsubsection{Treatment road}

Figure 5(a) and Figure 5(b) show the road with puddle forms being skimmed, filled and levelled off using good quality soil from the nearby area. The levelled road surfaces were then being ploughed by tractor with a mounted rotovator until the soils were reduced to a manageable form (Figure 5[c]). Based on the result obtained from the previous laboratory test (Figure 4), 20 wt. \% FJ-Ad was applied to treat the area together with the premixed Portland cement as shown in Figure 5(d). The mixed surface was sprayed with water, and later being rotovated thoroughly again as illustrated in Figure 5(e) and Figure 5(f) respectively. Finally, a road with the durable treated surface was successfully constructed as in Figure 5(g) and Figure 5(h). 

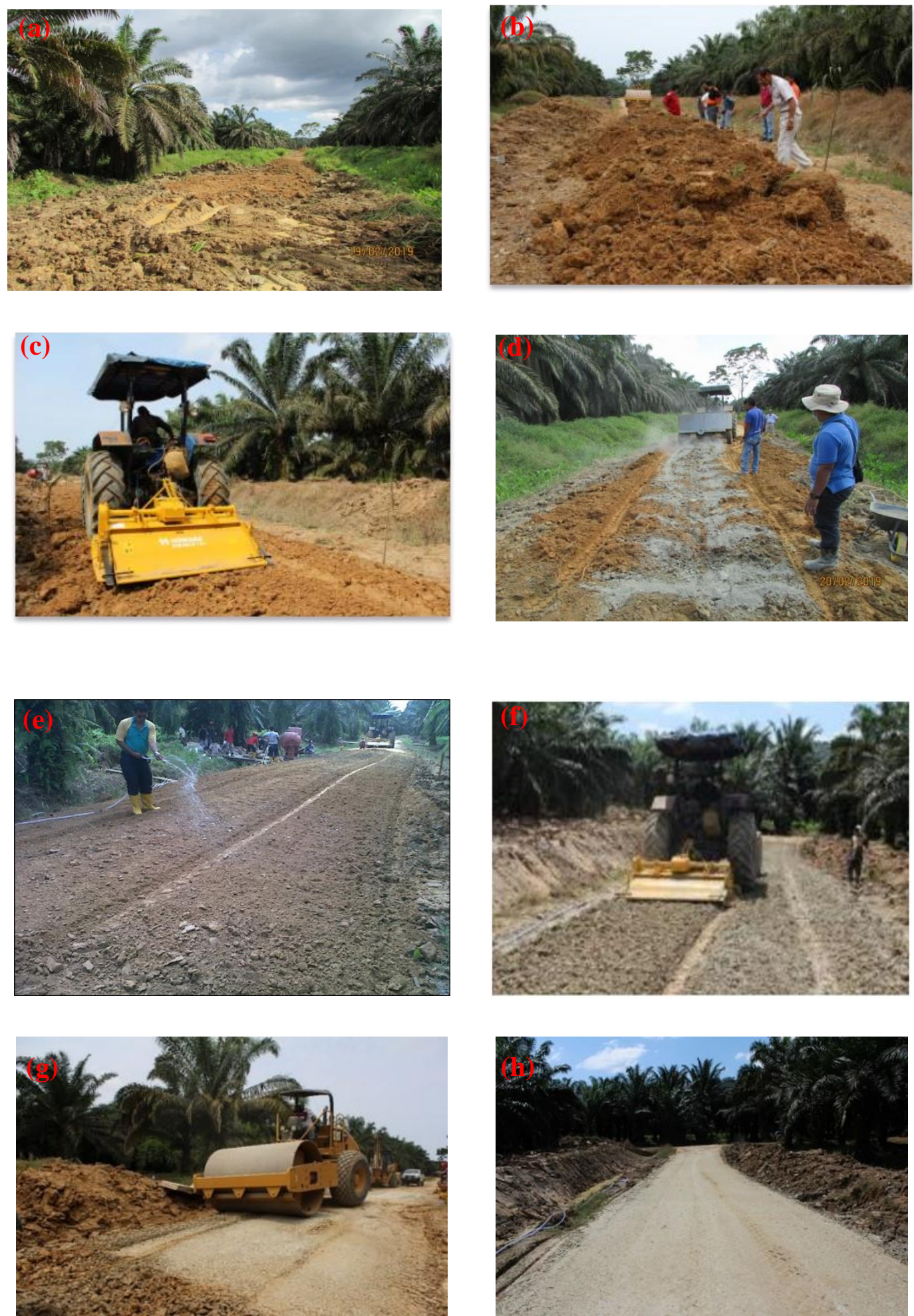

Figure 5. (a) Skimming the soft layer of road surface; (b) Importing quality soil from nearby area; (c) Rotovating the surface soil; (d) Distributing additive premix on road surface; (e) Watering the prepared surface; (f) Rotovating the prepared surface; (g) Compacting the prepared surface; (h) Completed treated road. 


\subsubsection{After treatment}

The earlier prepared Lahad Datu Station road with stabiliser had been subjected to three monsoon seasons for the past three years. Some sections of the road were under water from one to ten days, from a few centimetres to two metres deep. The roads were found to be in very good conditions in spite of being exposed to the extreme weather. No surface damage had been observed; thus, no road repair works were made to the road sections. The rainfall intensity during the period was very high which resulted in heavy silting problems in the side drains of undulating areas. Nevertheless, the road surfaces that had been treated with the stabiliser required less maintenance work as opposed to the situation before the stabiliser application. It was also observed that the amount of dust during dry days was much lesser compared to that of untreated road surface. Figure 6 shows the yearly conditions of the road which started after it was being constructed.

Trial 1

July 2014

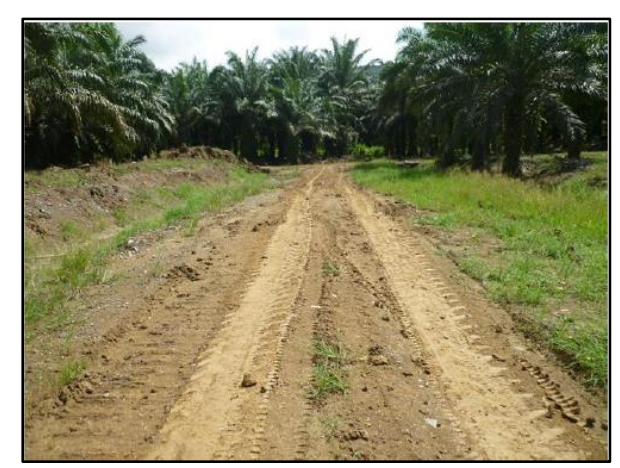

July 2015

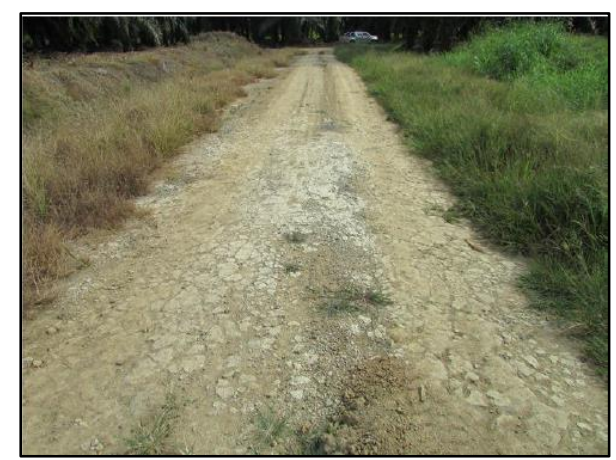

July 2016

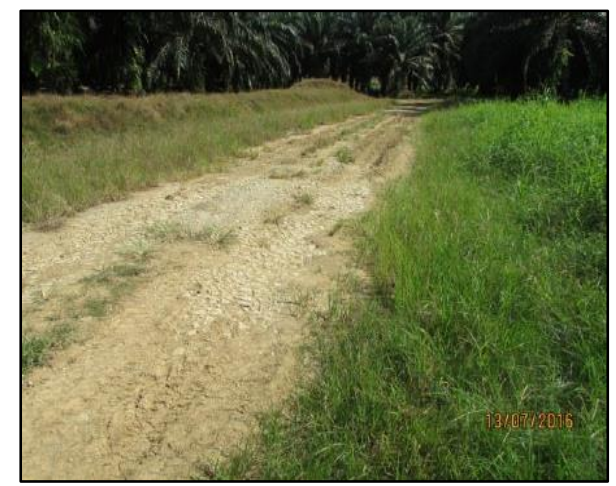

Trial 2
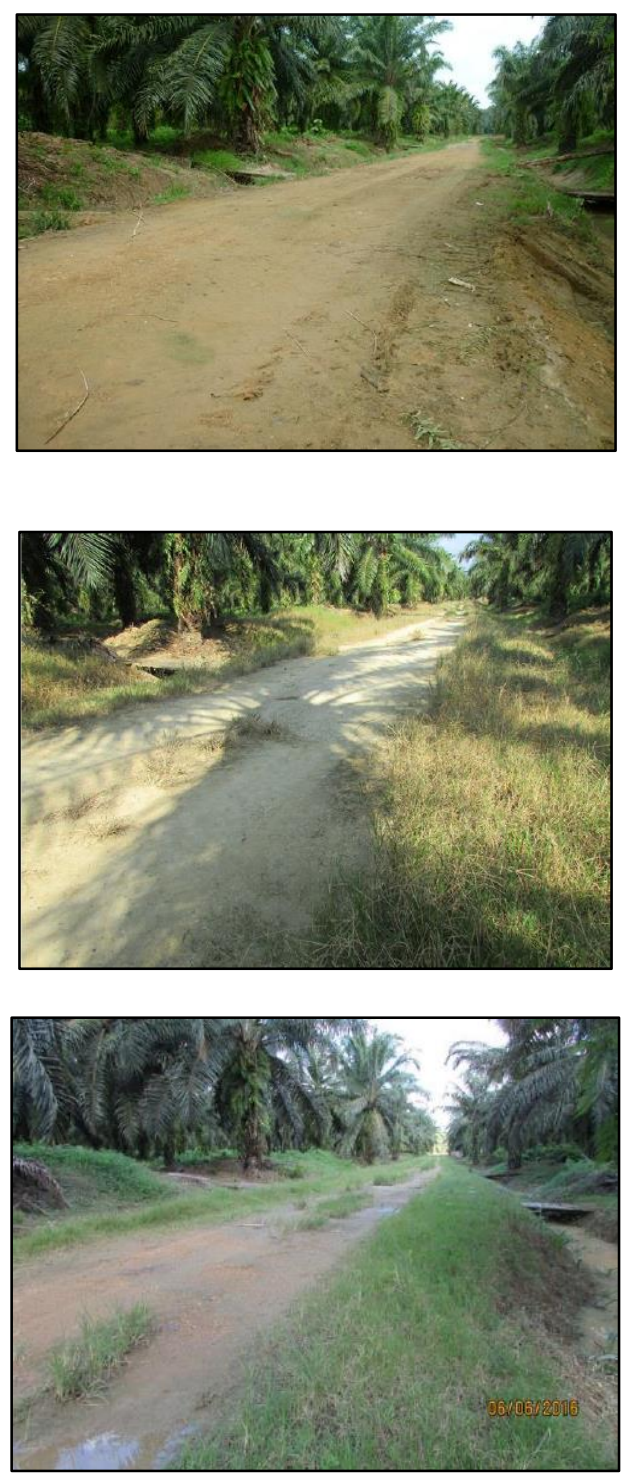
July 2017
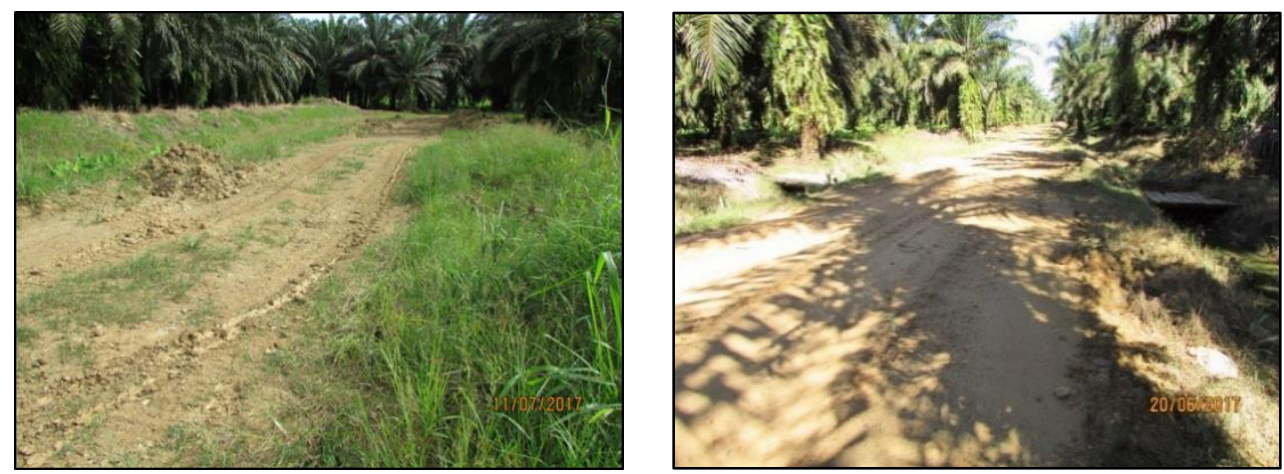

June 2018
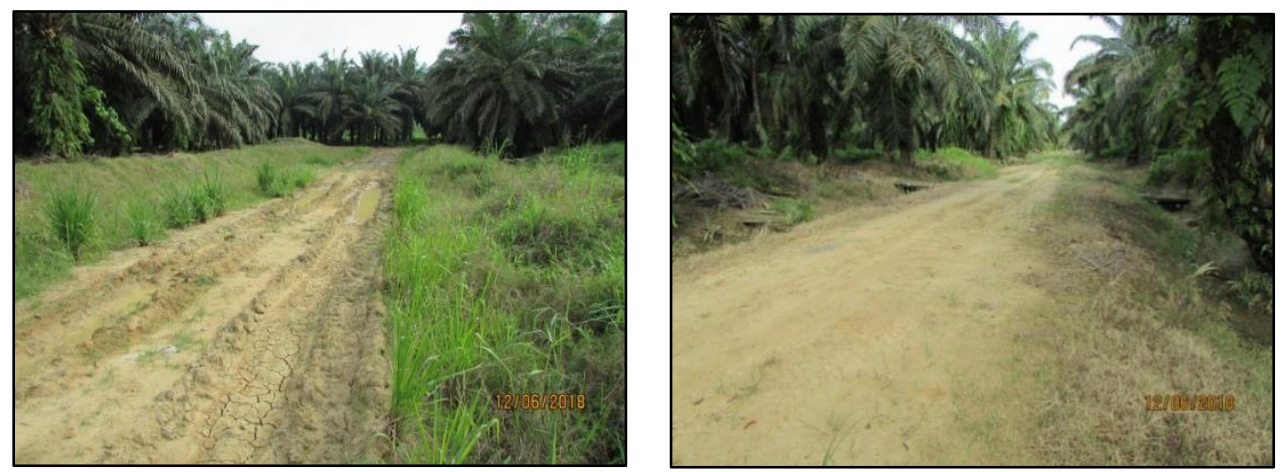

July 2019
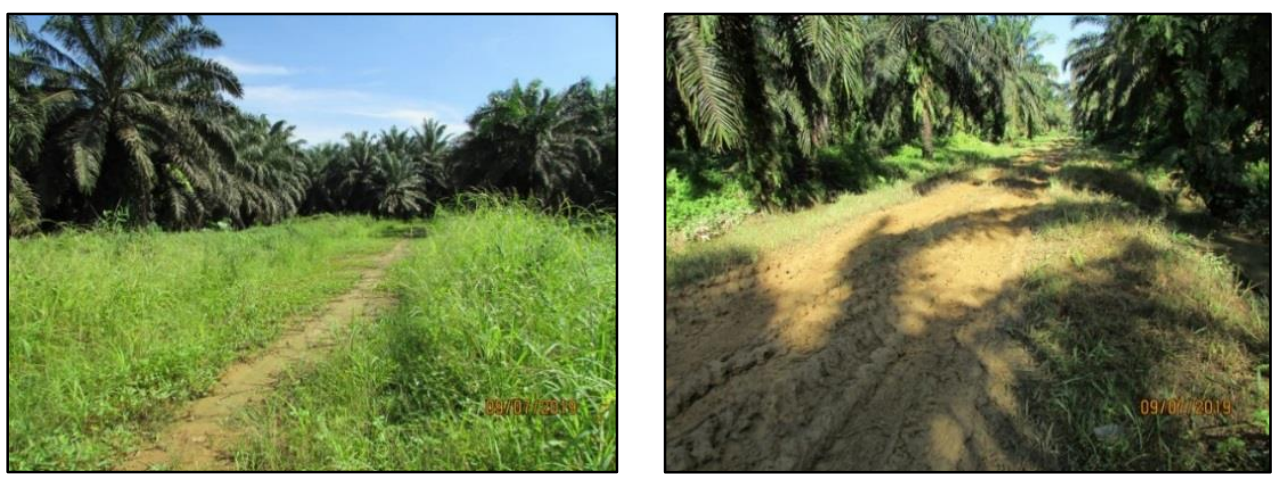

Figure 6. The pictures of road condition from 2016 to 2019.

\subsection{Cost Comparison}

In reference to Table 3, the application costs both for road maintenance using soil stabiliser and conventional were RM 79,500 and RM 82,500 respectively. The machineries required to carry out the road maintenance operation were almost the same for both methods i.e. roller compacter and tractor with different attachments, either back pusher bucket to level the crusher run after being poured on the road and soil rotovator was used to pulverise the soil prior to applying the soil stabiliser. The only additional implementation for soil stabiliser was a custom-made giant mixer pan. The pan was used to mix portland cement and soil stabiliser which later would be distributed on the application site. In terms of the overall cost, the soil stabiliser method was $6 \%$ to $7 \%$ cheaper compared to the conventional method. The other 
advantage of soil stabiliser that there was no need to import outside soil to do road maintenance, but the in-situ soil surface could be improved by adding the material. The cost of crusher run in this exercise was RM 60 per tonne, but this cost will vary according to the distance of source to the application site.

Table 3. The application costs both for road maintenance using soil stabiliser and conventional.
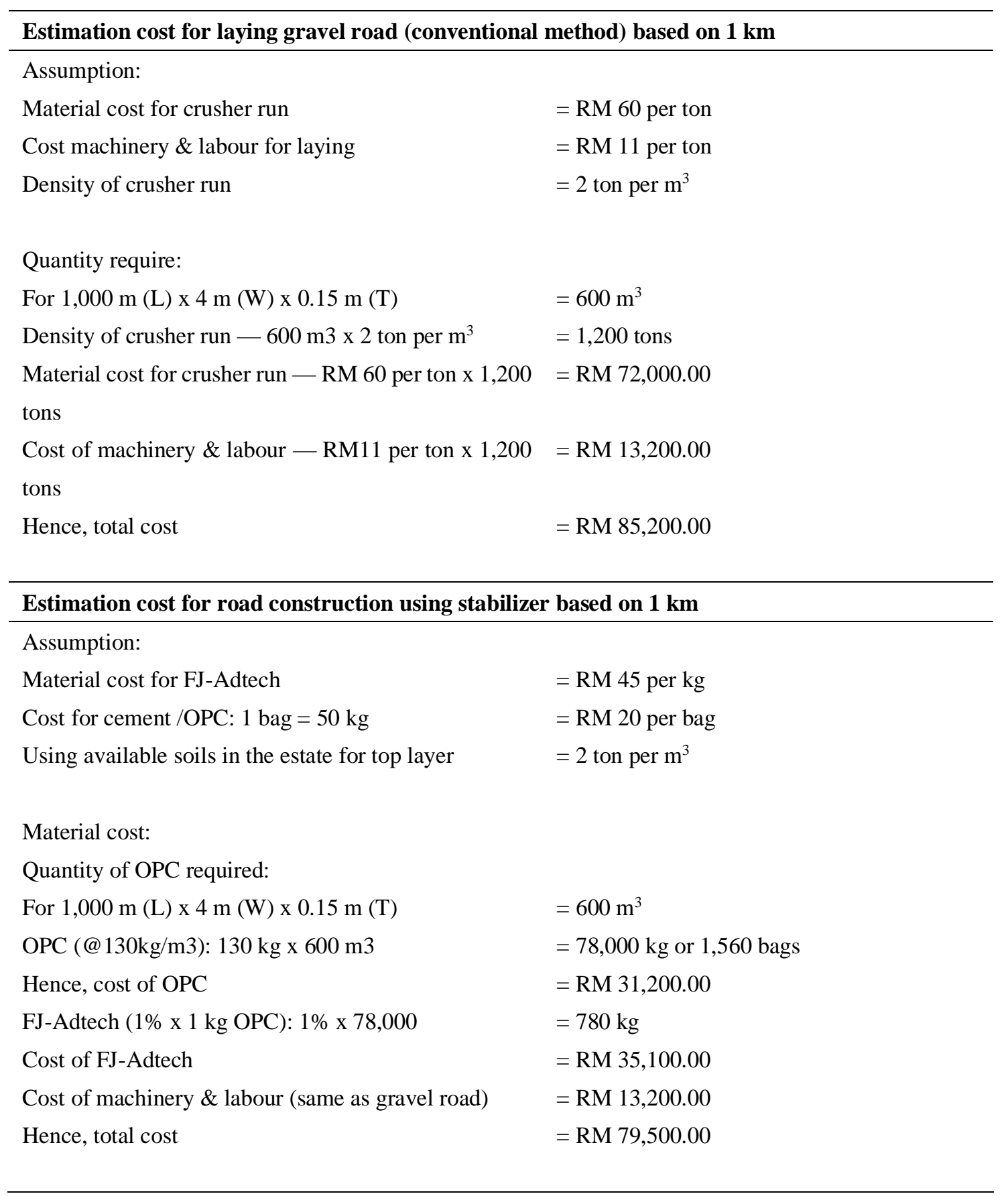


\section{Conclusion}

This study proved that the use of soil stabilisation allowed the unbound materials to be stabilised with cementation compound (cement, lime, fly ash, bitumen or their combinations) for greater strength, lower permeability and lower compressibility than the native soil. It is a cost saving for the plantation company if they opt for soil stabiliser method for road maintenance since the road constructed with stabiliser is usable in both dry and wet seasons. Furthermore, the presence of stabiliser is capable of making the road surfaces more durable when strengthening occurs progressively over time as treated soil cures. In conclusion, the in-situ soil can be treated with soil stabiliser in replacement of the use of the expensive crusher.

Acknowledgments: The authors would like to thank the Director General of MPOB for allowing this experimental study to be conducted at Lahad Datu Station, Sabah.

Conflicts of Interest: The authors declare no conflict of interest; in the collection, analyses, or interpretation of data; in the writing of the manuscript, or in the decision to publish the results.

\section{Reference}

Afandi, A. M., Tayeb, M. D., Sapudin, S., et al. (2001). Performance of oil palm on coral soils. Oil Palm Bulletin 44, 44, 1-18. Retrieved from http://palmoilis.mpob.gov.my/publications/OPB/opb44-afandi.pdf

Asgari, M. R., Baghebanzadeh Dezfuli, A., \& Bayat, M. (2015). Experimental study on stabilization of a low plasticity clayey soil with cement/lime. Arabian Journal of Geosciences, 8(3), 1439-1452. https://doi.org/10.1007/s12517013-1173-1

Firoozi, A. A., Guney Olgun, C., Firoozi, A. A., \& Baghini, M. S. (2017). Fundamentals of soil stabilization. International Journal of Geo-Engineering, 8(1). doi: 10.1186/s40703-017-0064-9.

Kushwaha, S. S., Kishan, D., \& Dindorkar, N. (2018). Stabilization of expansive soil using eko soil enzyme for highway embankment. Materials Today: Proceedings, 5(9), 19667-19679. https://doi.org/10.1016/j.matpr.2018.06.329

Lim, S. M., Wijeyesekera, D. C., Lim, A. J. M. S., et al. (2014). Critical review of innovative soil road stabilization techniques. International Journal of Engineering and Technology Research, 3(5), 204-211.

Makusa, G. P. (2012). Soil Stabilization Methods and Materials in Engineering Practice. Luleå University of Technology.

MPOB. (2020). Production of crude palm oil. Retrived from http://bepi.mpob.gov.my/index.php/statistics/production/135production-2015/736-production-of-crude-oil-palm-2015.html. 1727-1740

Paramananthan, S. (2013). Managing marginal soils for sustainable growth of oil palms in the tropics. Journal of Oil Palm and the Environment, 4(1), 1-16. https://doi.org/10.5366/jope.2013.1 
Phua, S. K. (2008). Oil plam cultivation - Drainaga, irrigation \& infrasructures (inland and coastal) [Lecture notes]. Intensive Diploma in Oil Palm Management Technology, Malaysian Palm Board, Ministry of Primary Industry. 316325.

Rauch, A. F., Harmon, J. S., Katz, L. E., et al. (2002). Measured effects of liquid soil stabilizers on engineering properties of clay. Transportation Research Record, (1787), 33-41. https://doi.org/10.3141/1787-04

Singh, R., Ray, D. S., Mehrotra, A., Afaque Khan, M. (2018). A review paper on comparative study of soil stabilization with widely used admixtures like lime, cement, flyash and bitumen emulsion. International Journal of Engineering Trends and Technology, 58(2), 96-99. doi: 10.14445/22315381/ijett-v58p218.

Veloo, R., Van Ranst, E., \& Selliah, P. (2015). Peat characteristics and its impact on oil palm yield. NJAS - Wageningen Journal of Life Sciences, 72, 33-40. https://doi.org/10.1016/j.njas.2014.11.001 